Handbook of Medical Electricity and RadioLOGY.

By James R. RIDdell. Edinburgh: E. and S. Livingstone. 1926. Pp. 239. 8s. 6d. net.

THe author, holding official positions at the University and the Western Infirmary, Glasgow, has a very large experience and has produced an excellent book. The first 50 pages treat of medical electricity, then follow 150 on the production, action, diagnostic application, and therapeutic uses of $X$ rays. The last three chapters are concerned with radium, light, and carbon dioxide snow. The text is very clear; it is illustrated by over 100 pictures. The book will be invaluable to anyone who feels he does not know much about the subject and wishes to have put before him the chief points about it in a concise way. Thus we imagine it will be a popular text-book for those who are beginning their study of a difficult department of medicine. Those holding the post of clerk or assistant in the electrical or radiological department of a hospital will be wise to get it as their first book.

\section{EDITORIAL NOTES}

Special Courses.

During the month of September the Fellowship of Medicine provides a varied choice of special courses to suit the increasing needs of practitioners for post-graduate medical study. Particulars of these can be obtained from the Secretary of the Fellowship at 1, Wimpole-street, W. 1, who will also supply the list of the remaining special courses for 1926. Taking the courses in order of date :-

From Sept. 6th to Oct. 2nd the honorary staff of the Central London Ophthalmic Hospital will provide clinical teaching in the afternoons from 2 o'clock in the out-patient department, as well as give lecture-demonstrations on the more important diseases of the eye. An operative surgery class will be held by arrangement for an additional fee.

Dr. Porter Phinlips, the superintendent, and the medical staff of the Bethlem Royal Hospital will give a series of lecture-demonstrations on Psychological Medicine from Sept. 7th to Oct. 2nd. The demonstrations are held bi-weekly at 11 A.M., so that, if desired, it is possible to undertake other post-graduate study simultaneously. In connexion with the Bethlem Royal Hospital a diploma course continuing for three months is held from the beginning of September. Entrants for the course who pay a composition fee of 15 guineas may, if due preliminary notice is given, attend either Part A or Part B of one course and postpone taking the remaining course until the next session. The fee for one part only is $\mathbf{1 0}$ guineas. Tickets for this course are issued by the Fellowship of Medicine which can also supply copies of the prospectus and time-table.

There will be a special course at the Infants Hospital, under the direction of Dr. ERIC PRITCHARD, for medical officers of welfare centres and others. This course occupies the afternoons only and is of a most comprehensive character, and opportunities are afforded to visit the Nursery Training School at the Hampstead Garden Suburb, the V.D. centre at Thavies Inn, Holborn, and the Blind Babies Home at Chorley Wood.
Radiotherapy in Relation to General Medicinô. By Francis Hernaman-Johnson, M.D. Londoff: Humphrey Milford, Oxford University Press. $19 \%$ Pp. 211 5s. net.

THIs admirable little book is stuffed full as an egg wi审h good matter. On p. 111 the author hints that he may appear to wander somewhat from his subject; this.is true, but we forgive him for his wanderings are very interesting and stimulate our thought. He opens with an excellent account of the physics of radiation and $\mathbb{E}_{s}$ effect on normal cells. Then there is a discursive chaptor on the general nature of disease and the action of remedie. The rest of the book - that is to say, considerably more the half-is clinical. This work is not a text-book for experte; it is an attempt to give the ordinary medical man an accoupt of the objects, the action, the possibilities, and limitations of radiotherapeutics. We think the author has succeeded in his task, and anyone who, not being a specialist, wishes to be aware of how and to what extent radiotherapy wettl help him is strongly advised to read this book.

Four lecture-demonstrations on treatment Electrotherapy will be given on successive Wednèsdays, beginning Sept. 22nd, at the Royal Frete Hospital by Dr. C. B. Heald. Although this course is intended primarily for general prostitioners desirous of familiarising themselves wigh the recent advances in medical electrical treatment, it is possible that it may appeal to many others wishful of becoming familiar with the subject awd with the popular sunlight treatment now advocat by so many medical advisers to the communito A new light department is in running order at the hospital.

The honorary staff of the National Orthopæ. Hospital have consented to give a second cotrise this year from Sept. 20th to Oct. 2nd. To those who followed the one in April this will be welcorfe news, as it is many years since a special course of instruction was available at the hospital. Lecture. demonstrations are arranged throughout the week on the various deformities and disabilities of thes particular branch of surgery. The entire clinical practice of the hospital is open to those enrolligig for the course, and a visit to Brockley Hill Country Hospital is included in the programme, whege opportunities for seeing cases of surgical tubercylosis are afforded.

For the general practitioner and others desirods of renewing their acquaintance with mode hospital practice the Westminster Hospital woill provide an intensive course from Sept. 20th Oct. 1st. The sessions are from 10.30 A.M. 重o 5.30 P.M. each day, and the work provided will include instruction in such subjects as genefl medicine, surgery, ophthalmology, laryngologen, gynæcology, chest and $\mathrm{X}$ ray work, \&c. A vi ist will be made to a mental institution connected with the hospital.

It must not be overlooked that the City $\frac{0}{7} \mathrm{f}$ London Maternity Hospital provides weekpy courses throughout the year in Obstetrics and Chitd Welfare. The course is limited to four graduats in any one given week and personal application $\mathrm{f} / \mathrm{r}$ permission to attend the course must be made कुo the Secretary of the Fellowship. Practical coures 